\title{
The Current State of Nuclear Electrical Power in the United States
}

\author{
Gary Sandquist* \\ University of Utah, USA
}

*Corresponding author: Gary Sandquist, Professor of Mechanical Engineering, University of Utah, USA.
Received Date: March 06, 2019

Published Date: March 13, 2019

\section{Opinion}

Although nuclear energy currently provides about $20 \%$ of U.S. electric power and over half of the nation's carbon free electricity, the ability of U.S. nuclear power plants to meet increasing demands for electricity and sustain the U.S. life style or even maintain the present one-fifth of US electrical demands is problematic and doubtful. A Union of Concerned Scientists (UCS) report finds that over one-third of the current fleet of 98 licensed nuclear power plants in the United States (65 PWRs and 33 BWRs) will or could be closed within the next decade. Sixty-six of these plants will not be profitable for continued operation by their plant owners. These closures will occur even before expiration of the plant's U.S. Government issued NRC License. Meanwhile, the U.S. and world demand for base-load electrical power will continue to escalate. Google now consumes more electrical power than San Francisco, and the advent of electrification of the U.S. vehicular fleet will impose even greater demands upon the U.S. electrical power sector. The average Chinese resident now consumes $3 \mathrm{~kW}$ while a U.S. resident uses about $10 \mathrm{~kW}$ on a $24 \mathrm{hr} / 7$ day basis while an African use only $0.5 \mathrm{~kW}$. Finally, over 1 billion people on the planet are without electricity today. These electrical power consumption rates will greatly increase in the future sustained by the use of coal and natural gas as the primary energy source. Globally, this increase will result in massive increases in greenhouse gases and exacerbate globally warming. There is little scientific doubt now, that this unmitigated human action is threatening the earth's biosphere, resulting in the marked increase in glacial water loss, severe weather disruptions, hurricanes, wild fires, flooding and uncontained biological stress of the planet's ecosystem. There are numerous reasons for the reversal of the optimistic projections for U.S. nuclear electrical power growth made in the 1970's and 1980's. It was projected that nuclear generated electrical power would be the primary driver of the U.S. electrical economy in the 21st century and would provide most U.S. base load electrical power without greenhouse gas emissions.

Now with real threats to the viability of U.S. nuclear capacity, natural gas must meet U.S. needs. U.S. renewables will provide some relief, but the absolute need for assured $24 / 7$ base-load electrical power is imperative. Fortunately, natural gas imposes only about one-half of the greenhouse gases associated with the combustion of coal, but most developing nations must rely on coal to meet their future electrical power needs. Some of the issues that suppress U.S. nuclear plant sustainment and future development include the abundance of cheap, natural gas for fossil fuel plants; rapid government approval and licensing of natural gas plants in contrast to the decade-long and often contentious path for nuclear plant licensing, the much lower cost and rapid gas plant construction, and finally the fear and opposition to nuclear plants because of the accidents at nuclear plants, especially the Russian Chernobyl Plant in 1985 and the 2011 Fukushima Accident. On 11 March 2011 the largest subsea bed earthquake ever recorded in Japan (a 9.0 to 9.1 Richter magnitude seismic event) caused a devastating tsunami to crash onto the Japanese coastline, causing no fewer than three meltdowns at the Fukushima nuclear plant, in addition to hydrogen-air explosions, the release of radioactive material, forged a lasting, distrust of the safety of nuclear energy throughout Japan and across the globe. Six reactors at the Fukushima Daiichi site are currently being dismantled as part of a cleanup process that will take decades to complete and is further complicated by technological challenges, public fear and residual radioactive waste. Currently, the large, multibillion-dollar U.S. nuclear plants such as the 1-Gigawatt Westinghouse, AP1000 plants under construction in South Carolina is now over budget and greatly delayed in licensing 
and construction. Such large nuclear plant result in cost and legal obstacles for siting nuclear plants in the US typically result in one or more decades of delays in construction and escalating costs.

Could a new type of nuclear power plant be designed and built with operation and safety guaranteed by basic laws of thermodynamics, engineering and physics. The world's civil aviation field has achieved aircraft that are reliable, safe, factory built, dependable and broadly accepted for their successful global operation. Could a smaller, robust nuclear electric plant be generating a few hundred Megawatts of electrical power on demand with assured safety and reliability that had been rigorously tested and assembled in controlled factory construction. A plant that meets highest, international standards for safety and operation. Indeed, a nuclear power plant that mirrored the international standards and expectation for safe operation under all environmental conditions. We expect and have achieved such products for safe and reliable air transportation. Can we also expect such performance from new nuclear power plants. Plant operators would be expected to meet high standards of training and operation. Furthermore, such plants would generate less waste and possibly even burn existing waste? A plant that slashes operating costs and avoids fears over accidents and nuclear proliferation? It is believed that such an advanced nuclear plant may achieved with the development of small modular reactors called SMRs. Development called UAMPS the book within factories or transportable and can be said so that they would provide reasonable pickle piper on the order 200 to 300 maybe what. Plants are sufficiently robust in the event of accident these plants maybe shut down rapidly and are self-contained with minimum risk of upset from severe conditions leading to release of radioactive materials to the environment.

SMRs advantages include the following: 1-controlled construction within a factory 2 -sufficiently small can be transported to the operational site and operated as needed to ride local electrical power on demand with her regional supply area. NRC is expected to certify NuScale's design SMR design. The company's first customer, Utah Associated Municipal Power Systems (UAMPS), is planning a 12-module SMR plant in Idaho for testing and certification slated for operation by mid-2020s based on certified design. SMRs respond to the most prevalent causes for fear and hesitation over nuclear power. Because reactor is modular and designed for replication, inherent safety features are built into plant. SMRs are designed with passive safety equipment so that, in case of an emergency or no power is available, reactors can operate safely for several days before manual intervention. Chances of a reactor meltdown are minimal because SMR design siphons heat away. SMRs plants offer several hundred megawatts of generating capacity. They are designed for modular construction, meaning parts can be put offsite, moved into place in power plant. Conversely, large-scale reactors are built on site from ground up, which calls large amount of land, materials, workers and equipment.

NuScale SMR is an advanced light-water reactor. Each module. Is a self-contained unit that operates independently within multimodule configuration. Up to 12 modules monitored \& operated from single control room. Reactor measures 65 feet tall and 9 feet in diameter. It sits within a containment vessel. Reactor and containment vessel operate inside a water-filled pool that is built below grade. Reactor operates using principles of natural circulation; hence, no pumps are needed to circulate water through reactor. Instead, system uses a convection process. Water is heated as it passes over core. Advanced SMRs offer many advantages such as relatively small size, reduced capital investment, ability to be sited in locations not possible for larger nuclear plants, and provisions for incremental power additions. SMRs offer the essential safety, safeguards, security and nonproliferation demanded in the 21 st Century.

\section{Acknowledgment}

None.

\section{Conflict of Interest}

No conflict of interest. 